Research Paper

\title{
A Nomogram based on Inflammatory Factors C-Reactive Protein and Fibrinogen to Predict the Prognostic Value in Patients with Resected Non-Small Cell Lung Cancer
}

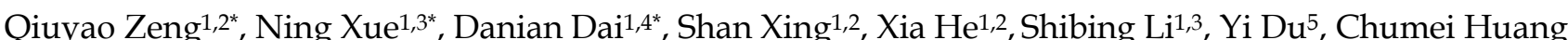
Linfang Li1 ${ }^{1,2}$, Wanli Liu ${ }^{1,2 \bowtie}$

1. State Key Laboratory of Oncology in Southern China, Collaborative Innovation Center for Cancer Medicine, Guangzhou, China;

2. Department of Clinical Laboratory, Sun Yat-sen University Cancer Center, Guangzhou, China;

3. Department of Experimental Research, Sun Yat-sen University Cancer Center, Guangzhou, China;

4. Department of Breast Oncology, Sun Yat-Sen University Cancer Center, Guangzhou, China;

5. School of Medical Laboratory Science, Guangdong Medical University, Dongguan, China;

6. Department of Laboratory Medicine, The First Affiliated Hospital of Sun Yat-Sen University, Guangzhou, China.

* Equal contributors.

$\triangle$ Corresponding authors: liuw1@sysucc.org.cn; Department of Clinical Laboratory, Sun Yat-sen University Cancer Center, 651 Dongfeng Road East, Guangzhou 510060, China. Tel./Fax: +86-20-8734-3192; lilf@sysucc.org.cn; Department of Clinical Laboratory, Sun Yat-sen University Cancer Center, 651 Dongfeng Road East, Guangzhou 510060, China. Tel./Fax: +86-20-8734-3438.

(C) Ivyspring International Publisher. This is an open access article distributed under the terms of the Creative Commons Attribution (CC BY-NC) license (https://creativecommons.org/licenses/by-nc/4.0/). See http://ivyspring.com/terms for full terms and conditions.

Received: 2016.09.01; Accepted: 2016.11.29; Published: 2017.02.25

\begin{abstract}
Purpose: This study aimed to develop an effective nomogram for predicting survival in surgically treated non-small cell lung cancer patients.

Methods: We retrospectively evaluated 856 NSCLC in this study. Cox regression analyses were performed to identify significant prognostic factors for developing a nomogram to predict overall survival (OS). The discriminative ability was assessed with the concordance index (C-index).

Results: On multivariate analysis of the 856 cohort, independent factors for survival were CRP, fibrinogen, tumor status, nodal status, distant metastasis and clinical stage, which were entered into the nomogram. The C-index of the established nomogram 0.720 ( $95 \% \mathrm{Cl}: 0.671-0.769)$ was higher than that of the seventh edition TNM staging system $0.689(95 \% \mathrm{Cl}: 0.668-0.709)$ for predicting $\mathrm{OS}(\mathrm{P}<0.05)$. Compared with patients with low CRP levels $(<8.6 \mathrm{~g} / \mathrm{L})$ and low fibrinogen levels $(<3.7 \mathrm{~g} / \mathrm{L})$, patients with high CRP and fibrinogen levels had shorter OS. Subgroup analyses revealed that the nomogram was a favorable prognostic parameter in stage I-IV NSCLC $(P<0.05)$.

Conclusion: A nomogram integrating CRP and fibrinogen, which could be convenient and feasible to obtain from the serum preoperatively, may assist in risk stratification for individual patient with resected NSCLC.
\end{abstract}

Key words: nomogram, NSCLC, prognosis.

\section{Introduction}

Lung cancer is still a leading cause of death among malignant tumors with 5-year survival rates of less than $15 \%$ [1]. It classified as either non-small cell lung cancer (NSCLC) or small cell lung cancer (SCLC) and NSCLC accounts for approximately $85 \%$ of incidents [2]. Numerous factors lead to the low survival rates in NSCLC patients, such as the poor early detection, tumor recurrence and distant metastasis. Recurrence and metastasis remain a great challenge for cure despite the excellent outcomes of NSCLC after standard treatments. Some parameters including tumor size, tumor location, differentiation 
grade and the TNM stages for predicting local recurrence, distant metastasis and overall survival in patients with NSCLC have been identified [3-5]. Although the stage determined according to the Union for International Cancer Control (UICC) and the International Association for the Study of Lung Cancer (IASLC) TNM classification is important and useful for predicting the clinical outcome and determining the appropriate treatment, the OS varies widely, even in patients with the same stage of NSCLC. Robust and reliable prognostic factors might be helpful to allow treatment options and follow-up schemes to be tailored to the individual risk situation. Thus, the identification of an efficient and reliable marker to obtain additional prognostic information is essential. Discovering low cost, highly effective and easily accessible biomarkers for assessment of lung cancer prognosis is necessary.

There has been shown that systemic inflammatory response reflect the promotion of angiogenesis, DNA damage and tumor invasion through up-regulation of cytokines [6-8]. Based on this, a number of inflammation-based prognostic markers have been identified, such as CRP and fibrinogen $[9,10]$. In addition, there is increasing evidence that serum CRP and plasma fibrinogen could effectively predict clinical outcome in patients with NSCLC [11-14]. Our previous results also showed that CRP was potential marker for poor prognosis in lung cancer [15]. Moreover, compared with other numerous prognostic factors, CRP and fibrinogen-based prognostic scores are simple, inexpensive and widely available from preoperative evaluation of blood test.

Recently, a growing studies reported that nomogram combined with the biomarkers of systemic inflammation response could provide more accurate prediction than conventional staging systems in a variety of tumors [16-19]. Nomograms are a pictorial representation of a complex mathematical formula. It use important factors to graphically depict a statistical prognostic model that used to estimate prognosis in oncology for a given individual [20]. Nomograms have been accepted as reliable and pragmatic prediction tools to quantify individual risk by incorporating a variety of important factors for oncological prognoses [21, 22]. In lung cancer, nomograms have been proved to provide more precise prediction compared with traditional TNM classification [23, 24]. However, there are few studies on establishing a prognostic nomogram for NSCLC based on CRP and plasma fibrinogen.

Herein, we established a prognostic nomogram for resettable NSCLC based on the clinicopathological parameters and the CRP and fibrinogen-based prognostic scores, to determine whether this model provides more accurate prediction of patient survival compared with the $7^{\text {th }}$ edition of AJCC TNM classifications.

\section{Methods}

\section{Sample collection and laboratory analysis}

We consecutively collected 856 lung cancer patients (ages 25-89 years, median 61 years, 612 males and 244 females) who underwent lung resection at Sun Yat-Sen University Cancer Center from December 2007 to October 2012. Inclusion criteria were as follows: (1) patients confirmed as lung cancer by pathological, pathologic slides were reviewed by two independent observers to classify histologic subtypes. (2) patients who underwent radical resection and had not previously taken anti-inflammatory medicines or anticoagulant therapy were included. (3) The absence of second carcinomas was assessed by clinical history, computed tomography (CT), ultra-sonographic examination and routine laboratory tests. Subjects with the following conditions were not included in the study: history of inflammatory disease that may modify CRP and fibrinogen levels, clinical suspicion or laboratory signs of bacterial or viral infection, fever of unknown origin. We collected clinicopathologic parameters of each patient as follows: age, gender, smoking history, tumor size, differentiation, pathologic TNM stage. Clinical stage was assessed according to the seventh edition of the Lung Cancer Staging International Division, which was published by the Union for International Cancer Control (UICC) and the International Association for the Study of Lung Cancer (IASLC) in 2009. Overall survival of patients was recorded based on a follow-up clinic or a telephone call. The date from surgery to death or to January 2015 was considered as survival time.

All the samples were collected at the time of diagnosis before any treatment. The serum CRP levels were assayed by nephelometry on an Automatic Biochemical Alnalyzer (Hitachi 7600, Japan) and plasma level of fibrinogen was measured by using a Dade thrombin reagent (Dade Behring, Germany) on an Automated Blood Coagulation Analyzer (CS-5100 Sysmex, Japan) according to the manufacturer's instructions.

\section{Risk Group Stratification Based on the Nomogram}

C-index was commonly used to evaluate the discrimination ability of a nomogram. Beyond this, according to the total risk scores (from highest to lowest) in the cohort, the NSCLC patients were grouped into different risk groups within a certain 
category, Kaplan-Meier curves were used to illustrate the survival outcomes of the NSCLC patients.

\section{Statistical Analysis}

All statistical analyses were performed using the SPSS 20.0 statistical package (SPSS Inc., Chicago, IL, USA). Nomograms for possible prognostic factors associated with overall survival (OS) were established by $\mathrm{R}$ software version 3.14 .1 (http:// www.rproject.org/), and the predictive performance of the model was evaluated by concordance index (C-index). Survival rates were analyzed using the Kaplan-Meier method and compared by the log-rank test. Univariate and multivariate survival analyses and Death hazard ratio were performed using the Cox proportional hazards regression with conditional backward stepwise to identify independent prognostic factors. Pearson's $\chi^{2}$ test and $t$-test was used to investigate the correlations between two categorical variables. Hazard ratios (HR) and 95\% confidence intervals (CI) were calculated using univariate and multivariate Cox proportional hazards regression models to estimate the effects of prognostic variables' OS. All statistical tests were two-tailed and we considered $P$ value less than 0.05 as statistically significant.

\section{Results}

\section{Clinicopathologic Characteristics}

856 patients met all criteria were enrolled for our study. The clinical characteristics of patients were shown in Table 1 . The median age was 61(range from 25 to 89 ). There existed 612 male patients $(71.5 \%)$ and 244 female patients $(28.5 \%)$. Over half patients (507, $59.23 \%)$ had smoking history. The number of patients of I, II, III and IV stage were 284 (16.94\%), 137 (16\%), $290(33.88 \%)$ and $145(16.94 \%)$ respectively. Lymph node metastasis was confirmed pathologically in 467 $(54.56 \%)$ patients. $712(83.18 \%)$ patients have distant metastasis. $290(33.88 \%)$ and $14(1.64 \%)$ patients have chemotherapy and radiotherapy respectively. And it included 538 adenocarcinoma (ADC), 256 squamous cell carcinoma (SCC), 4 large cell carcinoma (LC) and 58 other carcinomas.

\section{Association of preoperative serum CRP and plasma fibrinogen levels with clinical characteristics}

Median survival time in the present group of patients was 26 months (range 4-85 months), the death occurred in $618(72.20 \%)$ of the 856 lung cancer patients. The 3-, 5-year survival rate were $38.32 \%$, $15.78 \%$, respectively. Patient characteristics and correlations between preoperative CRP, fibrinogen levels and clinicopathological parameters are shown in Table 2. Male and ever smoking patients had higher preoperative CRP and fibrinogen levels $(P<0.001)$. And CRP and fibrinogen levels were also associated with tumor status, lymph node metastasis, distant metastases and clinical stage $(P<0.001)$. There was no correlation between fibrinogen, CRP and age, differentiation, chemotherapy, radiotherapy. Moreover, patients who experienced poor outcome had significantly higher preoperative CRP and fibrinogen levels compared to patients with better prognosis $(P<0.001)$.

Table 1. Clinicopathological characteristics of NSCLC patients.

\begin{tabular}{|c|c|c|c|}
\hline \multicolumn{2}{|c|}{ Demographic or characteristic } & \multirow{2}{*}{$\begin{array}{l}\text { Number } \\
612\end{array}$} & \multirow{2}{*}{$\begin{array}{l}\text { Percent(\%) } \\
71.5\end{array}$} \\
\hline Gender & male & & \\
\hline & famale & 244 & 28.5 \\
\hline \multirow[t]{2}{*}{ Age } & median & 61 & - \\
\hline & range & $25-89$ & - \\
\hline \multirow[t]{2}{*}{ Smoking history } & Yes & 507 & 59.23 \\
\hline & No & 349 & 40.77 \\
\hline \multirow{4}{*}{ Clinical stage } & I & 284 & 33.18 \\
\hline & II & 137 & 16 \\
\hline & III & 290 & 33.88 \\
\hline & IV & 145 & 16.94 \\
\hline \multirow[t]{4}{*}{ T status } & $\mathrm{T} 1$ & 145 & 16.94 \\
\hline & $\mathrm{T} 2$ & 488 & 57.01 \\
\hline & T3 & 111 & 13.97 \\
\hline & $\mathrm{T} 4$ & 112 & 13.08 \\
\hline \multirow[t]{4}{*}{$\mathrm{N}$ status } & No & 389 & 45.44 \\
\hline & N1 & 140 & 16.36 \\
\hline & N2 & 278 & 32.48 \\
\hline & N3 & 49 & 5.72 \\
\hline \multirow[t]{2}{*}{ M status } & M0 & 712 & 83.18 \\
\hline & M1 & 144 & 16.82 \\
\hline \multirow[t]{2}{*}{ Chemotherapy } & Yes & 290 & 33.88 \\
\hline & No & 566 & 66.12 \\
\hline \multirow[t]{2}{*}{ Radiotherapy } & Yes & 14 & 1.64 \\
\hline & No & 842 & 98.36 \\
\hline \multirow[t]{4}{*}{ Category } & adenocarcinoma(ADC) & 538 & 62.85 \\
\hline & squamous cell carcinoma(SCC) & 256 & 29.90 \\
\hline & large cell carcinoma(LC) & 4 & 0.47 \\
\hline & other & 58 & 6.78 \\
\hline
\end{tabular}

\section{Association of preoperative CRP and fibrinogen with survival}

X-tile program was used to determine the optimal cut-off values for CRP, fibrinogen of OS, which were $3.7 \mathrm{~g} / \mathrm{L}$ and $8.6 \mathrm{~g} / \mathrm{L}$, respectively (Figure 1). In NSCLC patients, the five-year OS rate was $15.78 \%$ (Figure 2A). Kaplan-Meier curves revealed that patients with higher level of pretreatment CRP and fibrinogen had a significantly shorter overall survival (Figure 2B, 2C, Table 3, $P<0.001$ ). Combined $\mathrm{CRP}$, fibrinogen expression and overall survival were also investigated. The patients were divided into three groups: both low, either high and both high. There was significant difference among three groups for overall survival (Figure 2D, Table $3, P<0.001$ ). The univariate analysis show that preoperative CRP and fibrinogen levels were found to be associated with OS, 
along with other variables, such as age, gender, smoking history, differentiation, tumor status, nodal status, clinical stage (Table 4 , all $P<0.05$ ). CRP and fibrinogen were identified as independent prognostic factor for OS using the Cox proportional hazard model (HR $=1.399,95 \%$ CI: 1.122-1.744, $P=0.003$; HR $=1.304,95 \%$ CI: 1.040-1.636, $P=0.022$, respectively). Moreover, multivariate analysis by Cox regression showed that tumor status $(\mathrm{HR}=1.281, P=0.009)$, nodal status $(\mathrm{HR}=1.721, P<0.001)$, distant metastases $(\mathrm{HR}=1.495, \mathrm{P}<0.001)$, clinical stage $(\mathrm{HR}=$ 2.009, $P<0.001)$ were as identified independent prognostic factors of overall survival for NSCLC patients.

\section{The nomogram for the prediction of OS}

To predict OS, two nomograms were established by multivariate Cox regression model according to all significantly independent factors for OS. A nomogram containing CRP, fibrinogen and TNM characteristics was developed based on the results of multivariate logistic regression analysis (Figure 3A), this nomogram achieved a C-index of 0.720 (95\% CI: 0.671-0.769) for OS prediction. The calibration curves for the probalility of survival at 5 years after surgery showed optimal agreement between the prediction established in the nomogram and the actual observation (Figure 3B). And the optimal cut-off value for fibrinogen and CRP of OS were $3.7 \mathrm{~g} / \mathrm{L}$ and $8.6 \mathrm{mg} / \mathrm{L}$, respectively. Another nomogram containing the TNM staging system achieved a C-index of 0.689 (95\% CI: 0.668-0.709) (Figure 3C), the calibration curves for the probalility of survival at 5 years after surgery were also fitted well (Figure 3D). Compared with the TNM staging system, the C-index of the CRP and fibrinogen nomogram was significantly higher than the C-index of the seventh TNM classification $(P<0.05)$. The results suggested that the nomogram based on CRP and fibrinogen is better than the AJCC TNM classifications in prognostic prediction. In addition, we have compared the predictive value of the nomogram with other currently available models [25-27] (Table S1 a,b,c).

Table 2. Correlation between Fibrinogen, CRP and clinicopathological variables of NSCLC patients.

\begin{tabular}{|c|c|c|c|c|c|c|c|c|c|c|c|}
\hline \multirow[t]{2}{*}{ Variables } & \multirow{2}{*}{$\begin{array}{l}\text { Cases } \\
(n=856)\end{array}$} & \multicolumn{2}{|c|}{ Fibrinogen $(3.7 \mathrm{~g} / \mathrm{L})$} & \multicolumn{3}{|l|}{ Patients, n (\%) } & \multicolumn{2}{|c|}{ CRP $(8.6 g / L)$} & \multicolumn{3}{|l|}{ Patients, n (\%) } \\
\hline & & Mean \pm SD & $P a$ & Low $(<3.7 \mathrm{~g} / \mathrm{L})$ & $\operatorname{High}(\geqq 3.7 \mathrm{~g} / \mathrm{L})$ & $P \mathrm{~b}$ & Mean \pm SD & $P a$ & Low $(<8.6 \mathrm{mg} / \mathrm{L})$ & High $(\geqq 8.6 \mathrm{mg} / \mathrm{L})$ & $P \mathrm{~b}$ \\
\hline Age (years) & & & 0.155 & & & 0.243 & & 0.968 & & & 0.926 \\
\hline$<=61$ & 119 & $3.61 \pm 1.38$ & & $73(61.3 \%)$ & $46(38.7 \%)$ & & $14.47 \pm 28.35$ & & $64(53.8 \%)$ & $55(46.2 \%)$ & \\
\hline$>61$ & 737 & $3.80 \pm 1.34$ & & $410(55.6 \%)$ & $327(44.4 \%)$ & & $14.37 \pm 24.41$ & & $393(53.3 \%)$ & $344(46.7 \%)$ & \\
\hline \multicolumn{12}{|l|}{ Gender } \\
\hline male & 612 & $3.91 \pm 1.41$ & $<0.001^{*}$ & $314(51.3 \%)$ & $298(48.7 \%)$ & $<0.001^{*}$ & $16.97 \pm 26.85$ & $<0.001^{*}$ & $280(45.8 \%)$ & $332(54.2 \%)$ & $<0.001^{*}$ \\
\hline Famale & 244 & $3.41 \pm 1.08$ & & $169(69.3 \%)$ & $75(30.7 \%)$ & & $7.90 \pm 17.96$ & & $177(72.5 \%)$ & $67(27.5 \%)$ & \\
\hline \multicolumn{12}{|l|}{$\begin{array}{l}\text { Smoking } \\
\text { history }\end{array}$} \\
\hline no & 349 & $3.46 \pm 1.15$ & $<0.001^{*}$ & $228(65.3 \%)$ & $121(34.7 \%)$ & $<0.001^{*}$ & $9.06 \pm 18.81$ & $<0.001^{*}$ & $235(67.3 \%)$ & $114(32.7 \%)$ & $<0.001^{*}$ \\
\hline yes & 507 & $3.98 \pm 1.42$ & & $255(50.3 \%)$ & $252(49.7 \%)$ & & $18.05 \pm 27.88$ & & $222(43.8 \%)$ & $285(56.2 \%)$ & \\
\hline \multicolumn{12}{|c|}{ Differentiation } \\
\hline G1 & 41 & $3.59 \pm 1.39$ & 0.388 & $25(61.0 \%)$ & $16(39.0 \%)$ & 0.547 & $13.77 \pm 26.87$ & 0.872 & $25(61.0 \%)$ & $16(39.0 \%)$ & 0.318 \\
\hline G2/G3 & 815 & $3.78 \pm 1.34$ & & $458(56.2 \%)$ & $357(43.6 \%)$ & & $14.41 \pm 24.89$ & & $432(53.0 \%)$ & $383(47.0 \%)$ & \\
\hline \multicolumn{12}{|c|}{$\begin{array}{l}\text { Tumor status } \\
\text { (T) }\end{array}$} \\
\hline T1/T2 & 633 & $3.57 \pm 1.24$ & $<0.001^{*}$ & $402(63.5 \%)$ & $231(36.5 \%)$ & $<0.001^{*}$ & $10.35 \pm 19.96$ & $<0.001^{*}$ & $389(61.5 \%)$ & $244(38.5 \%)$ & $<0.001^{*}$ \\
\hline T3/T4 & 223 & $4.33 \pm 1.46$ & & $81(36.3 \%)$ & $142(63.7 \%)$ & & $25.83 \pm 33.00$ & & $68(30.5 \%)$ & $155(69.5 \%)$ & \\
\hline \multicolumn{12}{|c|}{$\begin{array}{l}\text { Lymph node } \\
\text { metastasis }\end{array}$} \\
\hline No & 389 & $3.62 \pm 1.32$ & $0.003^{*}$ & $241(62.0 \%)$ & $148(38.0 \%)$ & $0.003^{*}$ & $11.10 \pm 20.82$ & $<0.001^{*}$ & $238(61.2 \%)$ & $151(38.8 \%)$ & $<0.001^{*}$ \\
\hline Yes & 467 & $3.89 \pm 1.36$ & & $242(51.8 \%)$ & $225(48.2 \%)$ & & $17.11 \pm 27.70$ & & $219(46.9 \%)$ & $248(53.1 \%)$ & \\
\hline \multicolumn{12}{|l|}{$\begin{array}{l}\text { Distant } \\
\text { metastases }\end{array}$} \\
\hline M0 & 712 & $3.71 \pm 1.33$ & $0.005^{*}$ & $418(58.7 \%)$ & $294(41.3 \%)$ & $0.003^{*}$ & $13.73 \pm 24.99$ & 0.091 & $392(55.1 \%)$ & $320(44.9 \%)$ & $0.03^{*}$ \\
\hline M1 & 144 & $4.06 \pm 1.40$ & & $65(45.1 \%)$ & $79(54.9 \%)$ & & $17.59 \pm 24.72$ & & $65(45.1 \%)$ & $79(54.9 \%)$ & \\
\hline \multicolumn{12}{|c|}{ Clinical stage } \\
\hline I/II & 421 & $3.55 \pm 1.30$ & $<0.001^{*}$ & $278(66.0 \%)$ & $143(34.0 \%)$ & $<0.001^{*}$ & $11.14 \pm 22.04$ & $<0.001^{*}$ & $264(62.7 \%)$ & $157(37.3 \%)$ & $<0.001^{*}$ \\
\hline III/IV & 435 & $3.98 \pm 1.35$ & & $205(47.1 \%)$ & $230(52.9 \%)$ & & $17.52 \pm 27.17$ & & $193(44.4 \%)$ & $242(55.6 \%)$ & \\
\hline \multicolumn{12}{|c|}{ Chemotherapy } \\
\hline No & 566 & $3.72 \pm 1.34$ & 0.141 & $326(57.6 \%)$ & $240(42.4 \%)$ & 0.334 & $13.61 \pm 24.41$ & 0.207 & $306(54.1 \%)$ & $260(45.9 \%)$ & 0.580 \\
\hline Yes & 290 & $3.86 \pm 1.36$ & & $157(54.1 \%)$ & $133(45.9 \%)$ & & $15.89 \pm 26.01$ & & $151(52.1 \%)$ & $139(47.9 \%)$ & \\
\hline \multicolumn{12}{|c|}{ Radiotherapy } \\
\hline No & 842 & $3.78 \pm 1.35$ & 0.059 & $473(56.2 \%)$ & $369(43.8 \%)$ & 0.290 & $14.46 \pm 25.13$ & 0.466 & $451(53.6 \%)$ & $391(46.4 \%)$ & 0.426 \\
\hline Yes & 14 & $3.09 \pm 0.97$ & & $10(71.4 \%)$ & $4(28.6 \%)$ & & $9.55 \pm 12.07$ & & $6(42.9 \%)$ & $8(57.1 \%)$ & \\
\hline \multicolumn{12}{|c|}{ Overall survial } \\
\hline Alive & 238 & $3.37 \pm 1.24$ & $<0.001^{*}$ & $177(74.4 \%)$ & $61(25.6 \%)$ & $<0.001^{*}$ & $7.98 \pm 17.17$ & $<0.001^{*}$ & $171(71.8 \%)$ & $67(28.2 \%)$ & $<0.001^{*}$ \\
\hline Death & 618 & $3.92 \pm 1.35$ & & $306(49.5 \%)$ & $312(50.5 \%)$ & & $16.85 \pm 27.00$ & & $286(46.3 \%)$ & $332(53.7 \%)$ & \\
\hline
\end{tabular}

Note: a Using t test, ${ }^{*} \mathrm{p}<0.05$ was considered statistically significant. $\mathrm{b}$ Using Chi-squared test, ${ }^{*} \mathrm{p}<0.05$ was considered statistically significant. 
A
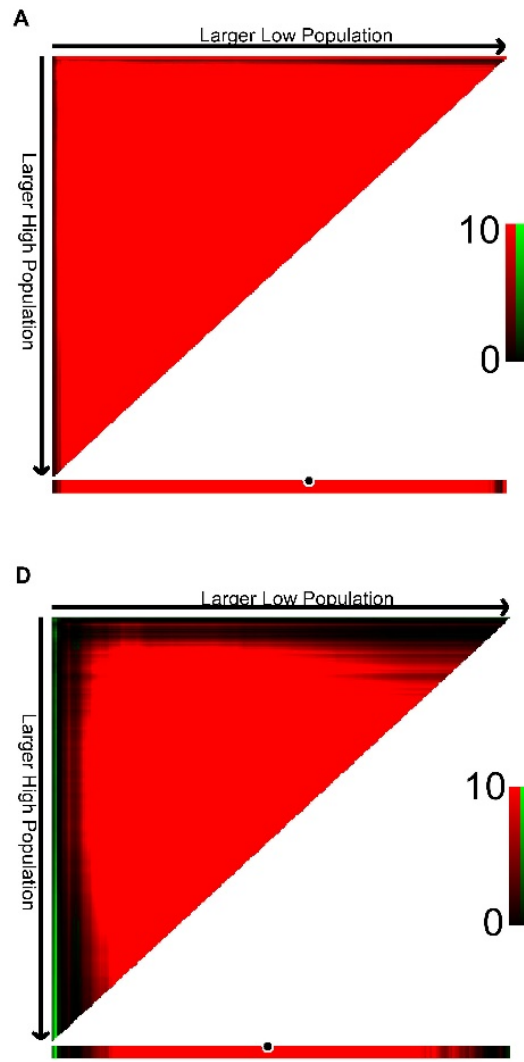
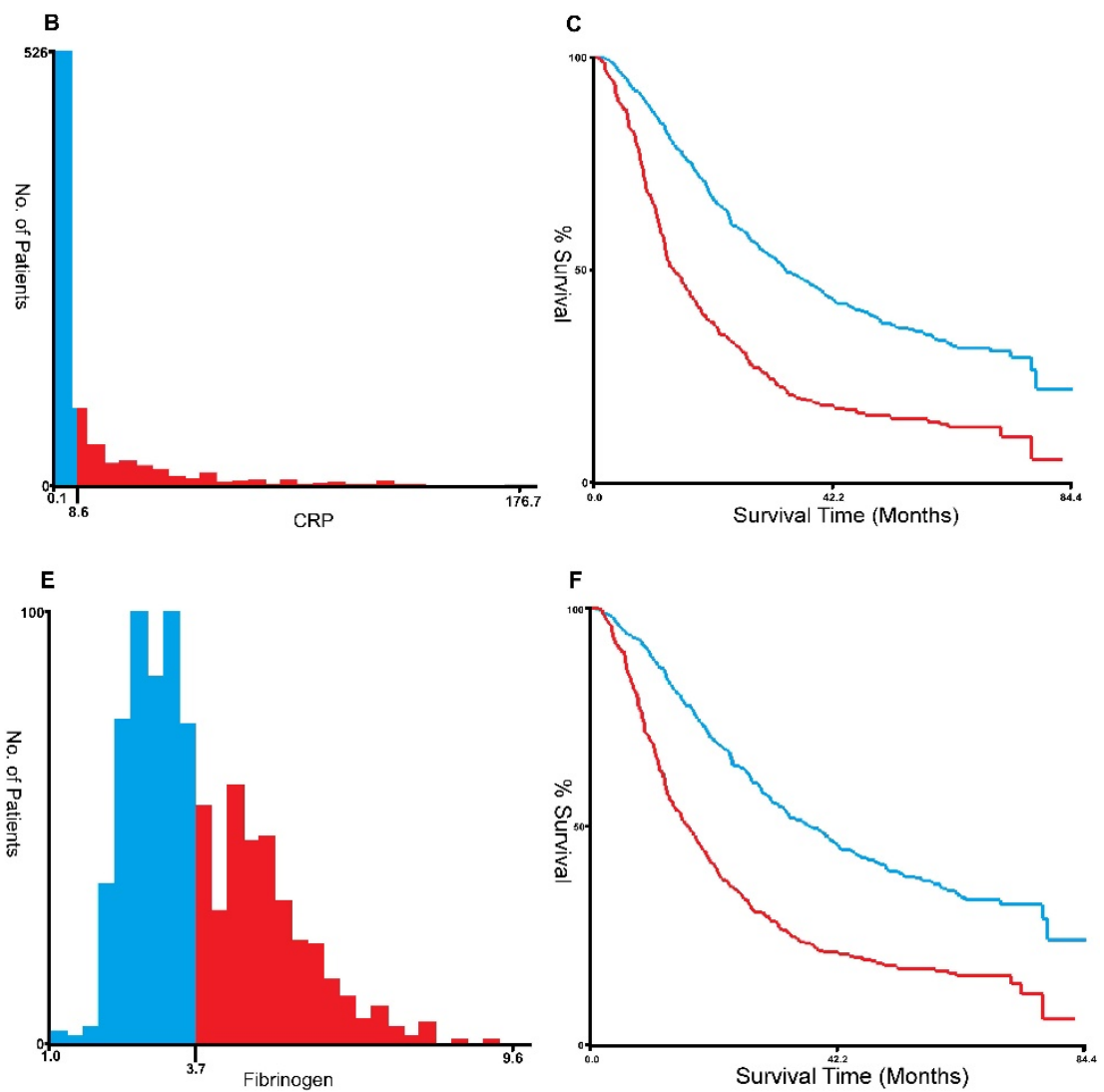

Figure 1. X-title analyses of 5-year OS was performed using patients' data to determine the optimal cut-off value for CRP (A, B, C) and fibrinogen (D, E, F).
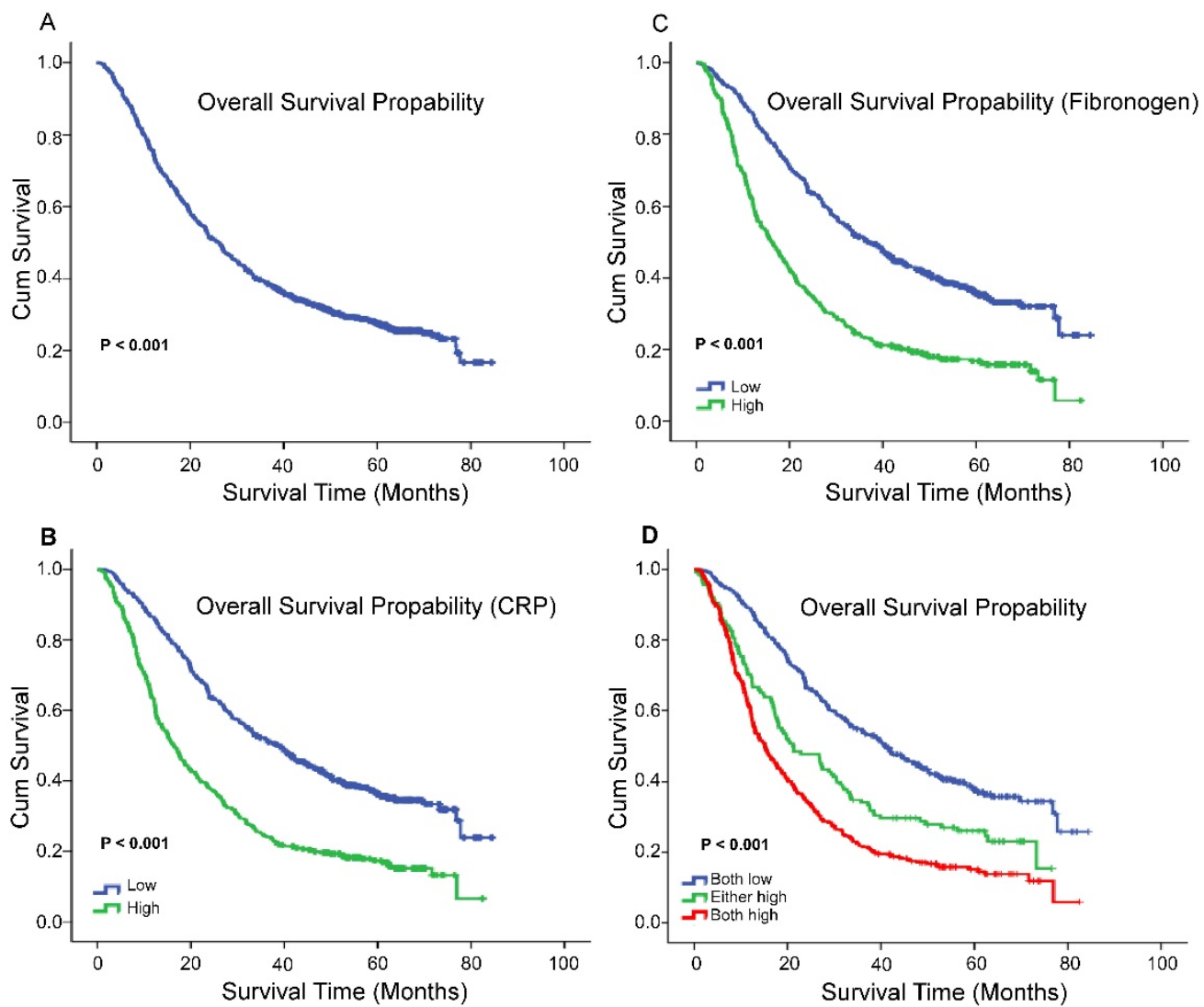

Figure 2. The 5 -year OS rate was $15.78 \%$ of 856 NSCLC patients(A); Survival curves for overall survival (OS) according to CRP (B), fibrinogen (C), and their combined (D) expression status. 
Table 3. Fibrinogen and CRP in patients with non-small cell lung cancer by Kaplan-Meier survival analysis (log-rank test).

\begin{tabular}{lcccc}
\hline Variable & Case & \multicolumn{2}{c}{ OS (months) } & \\
\cline { 3 - 4 } & & Mean & Median & $P$ value \\
\hline Total & 856 & & & $<0.001^{*}$ \\
$\begin{array}{l}\text { Fibrinogen } \\
\text { Low level }\end{array}$ & 483 & 44.752 & 37.233 & \\
$\begin{array}{l}\text { High levela } \\
\text { CRP }\end{array}$ & 373 & 26.623 & 16.3 & \\
$\begin{array}{l}\text { Low levela } \\
\text { High levela }\end{array}$ & 457 & 45.235 & 38.7 & $<0.001^{*}$ \\
$\begin{array}{l}\text { Combination } \\
\text { both low }\end{array}$ & 399 & 27.178 & 16.433 & \\
either high & & & & \\
both high & 401 & 46.874 & 40.867 & $<0.001^{*}$ \\
\hline
\end{tabular}

${ }^{*} \mathrm{p}<0.05$, statistically significant.

\section{Performance of the nomogram in stratifying risk of patients}

Based on the linear predictor of nomogram, four subgroups were divided in NSCLC patients after sorting by total score (score: 0-158, 158-258, 258-352, 2352) (Table 5, Table S2) and Kaplan-Meier curves were plotted, each of which represented a distinct prognosis. The NSCLC patients were stratified into different risk subgroups after applying the cutoff values. Moreover, there was significant distinction between Kaplan-Meier curves for survival outcomes within each TNM category $(P=0.0011, P=0.0421, P=$ $0.0041, P=0.0081$ ) (Figure 4). In all, this stratification could effectively discriminate the survival outcomes for the four proposed risk groups.

\section{Discussion}

NSCLC is an aggressive cancer with high incidence and death rate in worldwide [28]. The survival of individual patients are remarkably heterogeneous in NSCLC, even within the same stage [29]. The TNM staging system of NSCLC is commonly used for predicting cancer survival [30]. Nomogram is a simple graphical representation of a statistical prediction model that generates a numerical probability of a clinical event, such as death and cancer recurrence $[20,31]$. In recent years, nomograms have been constructed in a variety of cancers, and some of them have been found to be more reliable

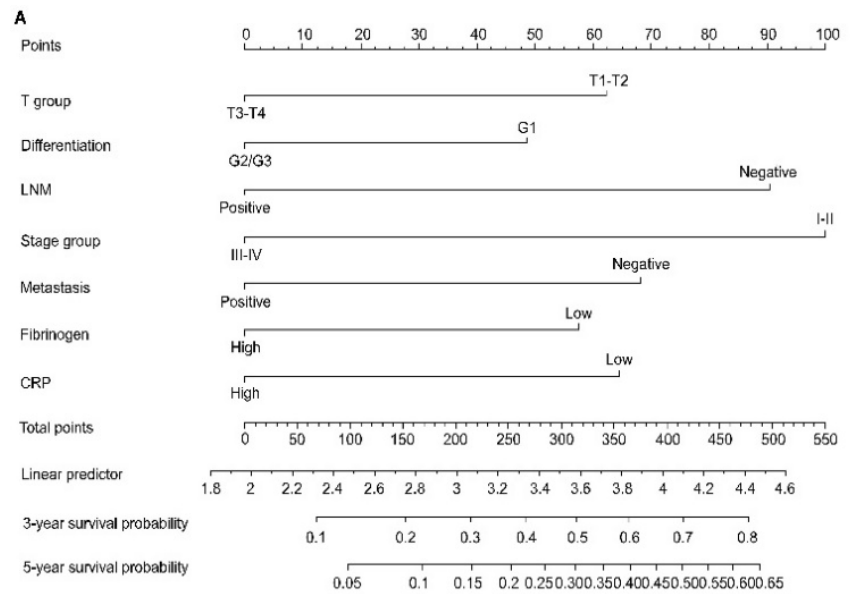

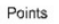

T group

LNM

Stage group

Metastasis

Total points

Linear predictor

3-year survival probability

5-year survival probability

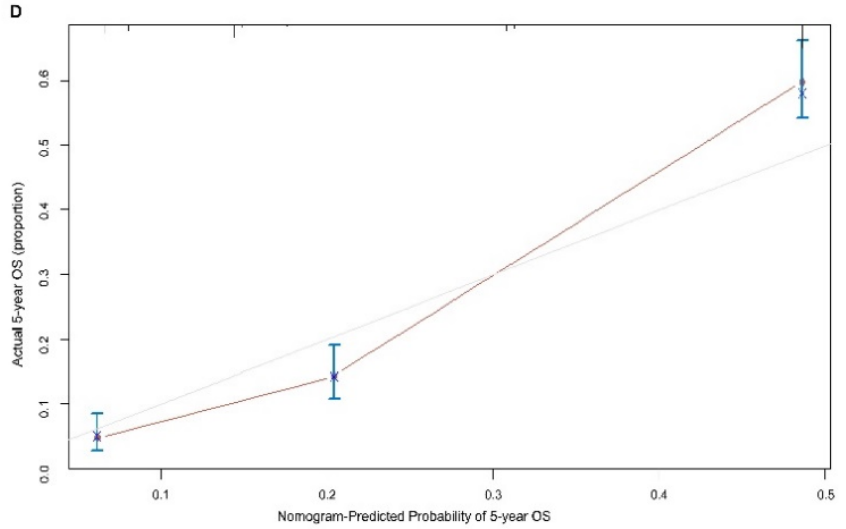

\begin{tabular}{llllllllllllll}
\hline 2 & 2.2 & 2.4 & 2.6 & 2.8 & 3 & 3.2 & 3.4 & 3.6 & 3.8 & 4 & 4.2
\end{tabular}

$\begin{array}{lllllllllllll}0.1 & 0.15 & 0.2 & 0.25 & 0.3 & 0.35 & 0.4 & 0.45 & 0.5 & 0.55 & 0.6 & 0.65 & 0.7\end{array}$ $\begin{array}{llllllllll}0.05 & 0.1 & 0.15 & 0.2 & 0.25 & 0.3 & 0.35 & 0.40 .45 & 0.5\end{array}$
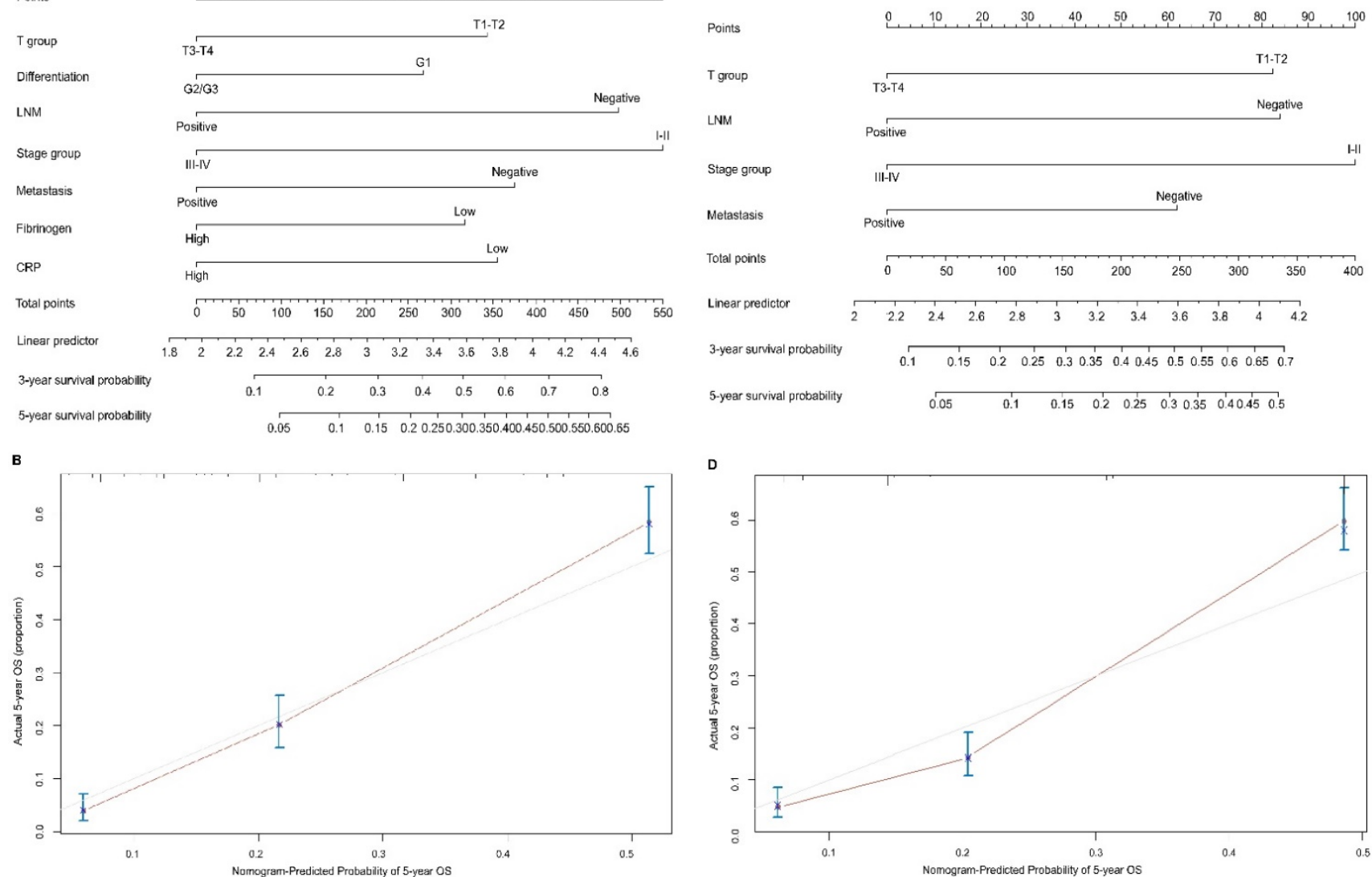

Figure 3. Nomogram convey the results of prognostic models using CRP, fibrinogen and TNM characteristics predict OS (A). Calibration curve for predicting 5 -year OS rate in the nomogram (B), the C-index for OS were 0.720 . Nomogram convey the results of prognostic models using TNM system staging (C). Calibration curve for predicting 5 -year OS rate in the nomogram (D), the C-index for OS were 0.689 . The $x$-axis is nomogram-predicted probility of survival and $y$-axis is actual survival. The reference line is 45 degree and indicates perfect calibration. 
prediction than the traditional staging system [23, 32-34]. Moreover it has been validated to compare favorably to the traditional TNM staging systems in many cancers, and thus have been identified as an alternative or even a new standard [22, 35, 36]. A number of studies also found that in patients with NSCLC, nomograms were accurate to predict the risk of a node's involvement $[37,38]$, the individual risk of developing metastasis to the brain and had strong performance in individualize patient decision making [39].

Table 4. Univariate and multivariate COX regression analyses for Overall Survival in patients with non-small cell lung cancer.

\begin{tabular}{|c|c|c|c|c|c|c|}
\hline \multirow[t]{2}{*}{ Variables } & \multicolumn{3}{|l|}{ Univariate analysis } & \multicolumn{3}{|c|}{ Multivariate analysis } \\
\hline & HR & $(95 \% \mathrm{CI})$ & $p$ value & HR & $(95 \% \mathrm{CI})$ & $p$ value \\
\hline Age (years), ( $\leq 61$ vs >61) & $0.969(0.772-1.215)$ & $0.772-1.215$ & 0.783 & & & \\
\hline Gender (female vs male) & $0.768(0.641-0.919)$ & $0.641-0.919$ & $0.004^{*}$ & $0.877(0.728-1.057)$ & $0.728-1.057$ & 0.169 \\
\hline Smoking history (no vs yes) & $1.129(0.961-1.327)$ & $0.961-1.327$ & 0.140 & & & \\
\hline \multicolumn{7}{|l|}{ Differentiation } \\
\hline G1 & reference & reference & reference & reference & reference & reference \\
\hline G2/G3 & $1.663(1.096-2.523)$ & $1.096-2.523$ & $0.017^{*}$ & $1.265(0.831-1.927)$ & $0.831-1.927$ & 0.273 \\
\hline \multicolumn{7}{|l|}{ Tumor status $(\mathrm{T})$} \\
\hline $\mathrm{T} 1 / \mathrm{T} 2$ & reference & reference & reference & reference & reference & reference \\
\hline $\mathrm{T} 3 / \mathrm{T} 4$ & $2.34(1.972-2.777)$ & $1.972-2.777$ & $<0.001^{*}$ & $1.281(1.063-1.542)$ & $1.063-1.542$ & $0.009^{*}$ \\
\hline Nodal status $(\mathrm{N}>0 / \mathrm{N} 0)$ & $3.154(2.651-3.751)$ & $2.651-3.751$ & $<0.001^{*}$ & $1.721(1.369-2.162)$ & $1.369-2.162$ & $<0.001^{*}$ \\
\hline Distant metastases (M0/M1) & $2.606(2.145-3.165)$ & 2.145-3.165 & $<0.001^{*}$ & $1.495(1.214-1.841)$ & $1.214-1.841$ & $<0.001^{*}$ \\
\hline \multicolumn{7}{|l|}{ Clinical stage } \\
\hline $\mathrm{I} / \mathrm{II}$ & reference & reference & reference & reference & reference & reference \\
\hline III/IV & $3.817(3.213-4.535)$ & $3.213-4.535$ & $<0.001^{*}$ & $2.009(1.562-2.583)$ & $1.562-2.583$ & $<0.001^{*}$ \\
\hline Fibrinogen (High/Low) & $2.064(1.761-2.420)$ & $1.761-2.420$ & $<0.001^{*}$ & $1.399(1.122-1.744)$ & $1.122-1.744$ & $0.003^{*}$ \\
\hline CRP (High/Low) & $2.047(1.746-2.401)$ & $1.746-2.401$ & $<0.001^{*}$ & $1.304(1.040-1.636)$ & $1.040-1.636$ & $0.022^{*}$ \\
\hline
\end{tabular}

${ }^{*} \mathrm{p}<0.05$, statistically significant. $\mathrm{CI}=$ confidence interval; $\mathrm{HR}=$ hazard ratio.
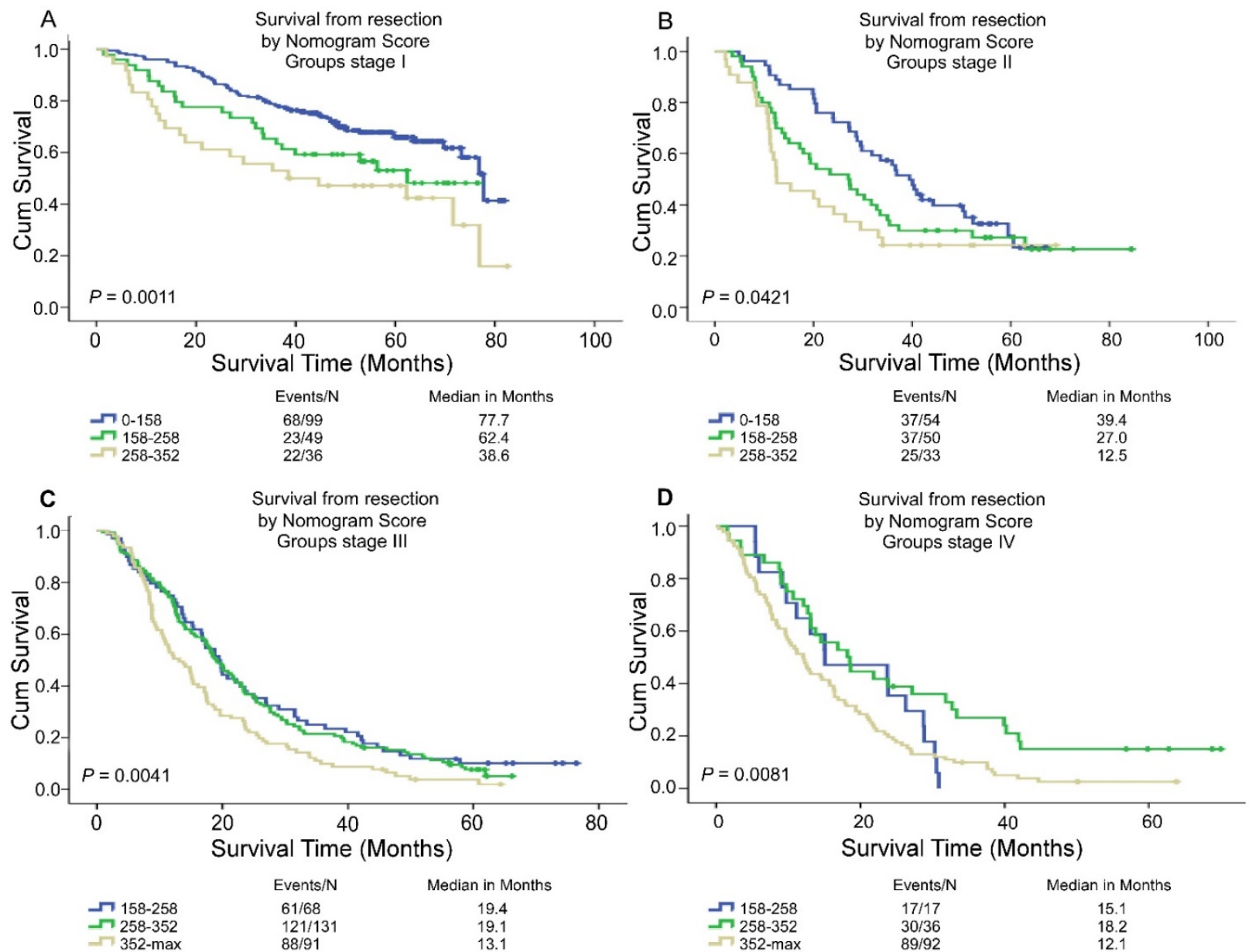

Figure 4. Risk group stratification within each TNM stage in the NSCLC patients. Kaplan-Meier curves of OS according to the score predicted OS shown in the nomograms. 
Table 5. Point Assignment and Prognostic Score of the nomogram based CRP and fibrinogen.

\begin{tabular}{lll}
\hline Variable and Prognostic Score Score & Estimated 5-Year Overall Survival (\%) \\
\hline T group Points & \\
T3-T4 & 0 \\
T1-T2 & 61 \\
Differentiation Points & \\
G2/G3 & 0 \\
G1 & 49 \\
LNM Points & \\
Positive & 0 \\
Negative & 89 \\
Stage group Points & \\
III-IV & 0 \\
I-II & 100 \\
Metastasis Points & & \\
Positive & 0 & \\
Negative & 66 & \\
Fibrinogen group Points & & \\
High & 0 & \\
Low & 56 & \\
CRP group Points & & \\
High & 0 & \\
Low & 64 & \\
Total prognostic Score & & 10 \\
0-158 & & 20 \\
158-258 & & 38 \\
258-352 & & 40 \\
$\geq 352$ & &
\end{tabular}

Numbers of studies suggested that serum CRP and plasma fibrinogen could be used as an independent prognostic factor for lung cancer [40-42]. However, studies combining the two-significant prognostic factor, serum CRP and plasma fibrinogen are rare. Could the combination achieve more efficient prognostic performance? Considering the advantage of clinical nomogram, we attempted to establish a predictive nomogram to predict the survival outcomes of resected NSCLC patients based on serum CRP, plasma fibrinogen and other prognostic factors. In this study, using univariable analysis and subsequent multivariable analysis, we identified tumor size, nodal status, distant metastases, clinical stage, fibrinogen and CRP as independent prognostic factors for surgically treated NSCLC patients. In line with the previous studies, the levels of CRP and fibrinogen were significant prognostic markers for resected NSCLC patients [11-14]. A nomogram for predicting survival was developed and these six variables were incorporated into the nomogram. The C-index of the nomogram based on CRP and fibrinogen predicted OS with an accuracy of 0.72 , which showed significantly better prediction of OS than the $7^{\text {th }}$ TNM staging system. The calibration plots revealed good correlation between the predicted survival probability and the actual survival rate. The decision curve analysis showed more potential of clinical application of the prediction models compared with TNM staging system. According to X-tile program, the cut-off value of CRP and fibrinogen were $8.6 \mathrm{mg} / \mathrm{L}, 3.7 \mathrm{~g} / \mathrm{L}$ respectively. The clinical characteristics of gender, smoking history, differentiation, tumor status, lymph node metastasis, distant metastases, clinical stage and overall survival were all associated with serum CRP and plasma fibrinogen levels. Even patients with the disease in same TNM category were divided into four risk groups, and each group had distinct survival outcomes in which patients in high-risk subgroup had shorter OS. Moreover, the measurement of serum CRP and plasma fibrinogen is relatively inexpensive and routinely conducted during preoperative examinations. Therefore our nomogram is a reliable tool to predict survival in resectable NSCLC and is helpful to make individualized treatment decision.

Several potential mechanisms can probably be used to explain the prognostic values of the inflammatory biomarker CRP and fibrinogen for NSCLC. Firstly, cancer cells interact directly and indirectly with host inflammatory cells. This tumor-associated inflammatory response may lead to an alteration in cancer cell biology and activation of stromal cells in the tumor microenvironment by up-regulation of cytokines and inflammatory mediators, such as interleukin-6 (IL-6), interleukin-1, interleukin-2, tumor necrosis factor (TNF), and these cytokines are all known to trigger the production of CRP and fibrinogen production [43, 44]. CRP is an acute-phase protein of inflammatory response, which is produced in the liver. It is very likely that the response to systemic inflammation makes CRP as important mediators linking inflammation and cancer $[45,46]$. Fibrinogen is primarily produced in the liver and is converted by the proteolytic action of thrombin. The elevated plasma fibrinogen levels reflect the status of tumor cell-host interactions, and the cellular interactions may be serving as an important contributing factor in cancer development including cell migration, promotion, and inflammatory mediators [47, 48]. Secondly, Evaluated CRP and fibrinogen are indicators of tumor-associated inflammatory response, which is companied by up-regulation of cytokines and inflammatory mediators, inhibition of apoptosis, induction of angiogenesis, stimulation of DNA damage and immunosuppression and remodelling of the extracellular matrix, hence promoting tumor growth and metastasis [6,7]. Thirdly, some growth factors, such as vascular endothelial growth factor (VEGF) and fibroblast growth factor (FGF-2), binds to fibrinogen and contact with tumor cells, thus promotes tumor proliferation and stimulates angiogenesis $[49,50]$. 
Although the nomogram in our study could predict survival more precise for patients with resected NSCLC, there are still several limitations in this study. First, this is a single-center study. Second, our study was a retrospective study, and there may exist selection bias during retrospective data collection. Third, it lacks validation cohort, which could further prove its robustness beyond current data. Therefore, our results need to be further verified in a prospective, large-scale collaborative study. Moreover, the detail mechanisms for better predictive value of CRP and fibrinogen were unknown, exploring the mechanisms of CRP and fibrinogen as independent prognostic factors for surgically treated NSCLC patients is our following aim.

In conclusion, we established a nomogram containing CRP and fibrinogen for predicting survival of patients with resected NSCLC, and it shows superior discrimination ability compared with traditional TNM staging. This model is a simple and easy-to-use scoring system for clinicians and patients to more precisely estimate the survival of individual patients after surgery and identify subgroups of patients who are in need of a specific treatment strategy.

\section{Supplementary Material}

Supplementary tables.

http://www.jcancer.org/v08p0744s1.pdf

\section{Acknowledgments}

This study was supported by grants from the National Natural Science Foundation of China (81271902 and 81472008).

\section{Competing Interests}

The authors have declared that no competing interest exists.

\section{References}

1. Kamangar F, Dores GM, Anderson WF. Patterns of cancer incidence, mortality, and prevalence across five continents: defining priorities to reduce cancer disparities in different geographic regions of the world. J Clin Oncol 2006; $24: 2137-2150$.

2. Siegel RL, Miller KD, Jemal A. Cancer statistics, 2015. CA Cancer J Clin 2015; 65: 5-29.

3. Agarwal M, Brahmanday G, Chmielewski GW, Welsh RJ, Ravikrishnan KP. Age, tumor size, type of surgery, and gender predict survival in early stage (stage I and II) non-small cell lung cancer after surgical resection. Lung Cancer 2010; 68: 398-402.

4. Osarogiagbon RU, Ogbata O, Yu X. Number of lymph nodes associated with maximal reduction of long-term mortality risk in pathologic node-negative non-small cell lung cancer. Ann Thorac Surg 2014; 97: 385-393.

5. Nakamura H, Taniguchi Y, Miwa K, Adachi Y, Fujioka S, Haruki T et al. Comparison of the surgical outcomes of thoracoscopic lobectomy, segmentectomy, and wedge resection for clinical stage I non-small cell lung cancer. Thorac Cardiovasc Surg 2011; 59: 137-141.

6. Coussens LM, Werb Z. Inflammation and cancer. Nature 2002; 420: 860-867.

7. Balkwill F, Mantovani A. Inflammation and cancer: back to Virchow? Lancet 2001; 357: 539-545.

8. Jaiswal M, LaRusso NF, Burgart LJ, Gores GJ. Inflammatory cytokines induce DNA damage and inhibit DNA repair in cholangiocarcinoma cells by a nitric oxide-dependent mechanism. Cancer Res 2000; 60: 184-190.
9. Jamieson NB, Glen P, McMillan DC, McKay CJ, Foulis AK, Carter R et al. Systemic inflammatory response predicts outcome in patients undergoing resection for ductal adenocarcinoma head of pancreas. Br J Cancer 2005; 92: 21-23.

10. Zhang D, Zhou X, Bao W, Chen Y, Cheng L, Qiu G et al. Plasma fibrinogen levels are correlated with postoperative distant metastasis and prognosis in esophageal squamous cell carcinoma. Oncotarget 2015; 6: 38410-38420.

11. Tomita M, Shimizu T, Ayabe T, Nakamura K, Onitsuka T. Elevated preoperative inflammatory markers based on neutrophil-to-lymphocyte ratio and C-reactive protein predict poor survival in resected non-small cell lung cancer. Anticancer Res 2012; 32: 3535-3538.

12. Gagnon B, Abrahamowicz M, Xiao Y, Beauchamp ME, MacDonald N, Kasymjanova $\mathrm{G}$ et al. Flexible modeling improves assessment of prognostic value of C-reactive protein in advanced non-small cell lung cancer. Br J Cancer 2010; 102: 1113-1122.

13. Kim KH, Park TY, Lee JY, Lee SM, Yim JJ, Yoo CG et al. Prognostic significance of initial platelet counts and fibrinogen level in advanced non-small cell lung cancer. J Korean Med Sci 2014; 29: 507-511.

14. Jiang HG, Li J, Shi SB, Chen P, Ge LP, Jiang $Q$ et al. Value of fibrinogen and $\mathrm{D}$-dimer in predicting recurrence and metastasis after radical surgery for non-small cell lung cancer. Med Oncol 2014; 31: 22.

15. Zhang XY, Zhang G, Jiang Y, Liu D, Li MZ, Zhong Q et al. The prognostic value of serum C-reactive protein-bound serum amyloid A in early-stage lung cancer. Chin J Cancer 2015; 34: 335-349.

16. Deng $Q$, He B, Liu X, Yue J, Ying H, Pan $Y$ et al. Prognostic value of pre-operative inflammatory response biomarkers in gastric cancer patients and the construction of a predictive model. J Transl Med 2015; 13: 66.

17. Ku JH, Kang M, Kim HS, Jeong CW, Kwak C, Kim HH. The prognostic value of pretreatment of systemic inflammatory responses in patients with urothelial carcinoma undergoing radical cystectomy. Br J Cancer 2015; 112: 461-467.

18. Szkandera J, Gerger A, Liegl-Atzwanger B, Absenger G, Stotz M, Friesenbichler J et al. The lymphocyte/monocyte ratio predicts poor clinical outcome and improves the predictive accuracy in patients with soft tissue sarcomas. Int J Cancer 2014; 135: 362-370.

19. Szkandera J, Gerger A, Liegl-Atzwanger B, Absenger G, Stotz M, Samonigg H et al. Validation of the prognostic relevance of plasma C-reactive protein levels in soft-tissue sarcoma patients. Br J Cancer 2013; 109: 2316-2322.

20. Balachandran VP, Gonen M, Smith JJ, DeMatteo RP. Nomograms in oncology: more than meets the eye. Lancet Oncol 2015; 16: e173-180.

21. Xu L, Peng ZW, Chen MS, Shi M, Zhang YJ, Guo RP et al. Prognostic nomogram for patients with unresectable hepatocellular carcinoma after transcatheter arterial chemoembolization. J Hepatol 2015; 63: 122-130.

22. Zou Q, Li J, Wu D, Yan Z, Wan X, Wang K et al. Nomograms for Pre-operative and Post-operative Prediction of Long-Term Survival of Patients Who Underwent Repeat Hepatectomy for Recurrent Hepatocellular Carcinoma. Ann Surg Oncol 2016; 23: 2618-2626.

23. Wang Y, Li J, Xia Y, Gong R, Wang K, Yan Z et al. Prognostic nomogram for intrahepatic cholangiocarcinoma after partial hepatectomy. J Clin Oncol 2013; 31: 1188-1195.

24. Zaak D, Burger M, Otto W, Bastian PJ, Denzinger S, Stief CG et al. Predicting individual outcomes after radical cystectomy: an external validation of current nomograms. BJU Int 2010; 106: 342-348.

25. Oberije C, De Ruysscher D, Houben R, van de Heuvel M, Uyterlinde W, Deasy JO et al. A Validated Prediction Model for Overall Survival From Stage III Non-Small Cell Lung Cancer: Toward Survival Prediction for Individual Patients. International Journal of Radiation Oncology Biology Physics 2015; 92: 935-944.

26. Tanvetyanon T, Finley DJ, Fabian T, Riquet M, Voltolini L, Kocaturk C et al. Prognostic Nomogram to Predict Survival After Surgery for Synchronous Multiple Lung Cancers in Multiple Lobes. Journal of Thoracic Oncology 2015; 10: 338-345.

27. Liang WH, Zhang L, Jiang GN, Wang $\mathrm{Q}$, Liu LX, Liu DR et al. Development and Validation of a Nomogram for Predicting Survival in Patients With Resected Non-Small-Cell Lung Cancer. Journal of Clinical Oncology 2015; 33: 861.

28. Gloeckler Ries LA, Reichman ME, Lewis DR, Hankey BF, Edwards BK. Cancer survival and incidence from the Surveillance, Epidemiology, and End Results (SEER) program. Oncologist 2003; 8: 541-552.

29. Nesbitt JC, Putnam JB, Jr, Walsh GL, Roth JA, Mountain CF. Survival in early-stage non-small cell lung cancer. Ann Thorac Surg 1995; 60: 466-472.

30. Birim O, Kappetein AP, Waleboer M, Puvimanasinghe JP, Eijkemans MJ, Steyerberg EW et al. Long-term survival after non-small cell lung cancer surgery: development and validation of a prognostic model with a preoperative and postoperative mode. J Thorac Cardiovasc Surg 2006; 132: 491-498.

31. Iasonos A, Schrag D, Raj GV, Panageas KS. How to build and interpret a nomogram for cancer prognosis. J Clin Oncol 2008; 26: 1364-1370.

32. Graesslin O, Abdulkarim BS, Coutant C, Huguet F, Gabos Z, Hsu L et al. Nomogram to predict subsequent brain metastasis in patients with metastatic breast cancer. J Clin Oncol 2010; 28: 2032-2037.

33. Sternberg CN. Are nomograms better than currently available stage groupings for bladder cancer? J Clin Oncol 2006; 24: 3819-3820.

34. Touijer K, Scardino PT. Nomograms for staging, prognosis, and predicting treatment outcomes. Cancer 2009; 115: 3107-3111. 
35. Li Y, Jia H, Yu W, Xu Y, Li X, Li Q et al. Nomograms for predicting prognostic value of inflammatory biomarkers in colorectal cancer patients after radical resection. Int J Cancer 2016; 139: 220-231.

36. Tang LQ, Li CF, Li J, Chen WH, Chen QY, Yuan LX et al. Establishment and Validation of Prognostic Nomograms for Endemic Nasopharyngeal Carcinoma. J Natl Cancer Inst 2016; 108.

37. Mattes MD, Weber WA, Foster A, Moshchinsky AB, Ahsanuddin S, Zhang Z et al. A Predictive Model for Lymph Node Involvement with Malignancy on PET/CT in Non-Small-Cell Lung Cancer. J Thorac Oncol 2015; 10: 1207-1212.

38. Jiang L, Jiang S, Lin Y, Yang H, Xie Z, Lin Y et al. Nomogram to Predict Occult N2 Lymph Nodes Metastases in Patients With Squamous Nonsmall Cell Lung Cancer. Medicine (Baltimore) 2015; 94: e2054.

39. Won YW, Joo J, Yun T, Lee GK, Han JY, Kim HT et al. A nomogram to predict brain metastasis as the first relapse in curatively resected non-small cell lung cancer patients. Lung Cancer 2015; 88: 201-207.

40. Chaturvedi AK, Caporaso NE, Katki HA, Wong HL, Chatterjee N, Pine SR et al. C-reactive protein and risk of lung cancer. J Clin Oncol 2010; 28: 2719-2726.

41. Tolia M, Tsoukalas N, Kyrgias G, Mosa E, Maras A, Kokakis I et al. Prognostic Significance of Serum Inflammatory Response Markers in Newly Diagnosed Non-Small Cell Lung Cancer before Chemoirradiation. Biomed Res Int 2015; 2015: 485732.

42. Tulek B, Koylu H, Kanat F, Arslan U, Ozer F. Serum C-reactive protein and procalcitonin levels in non-small cell lung cancer patients. Contemp Oncol (Pozn) 2013; 17: 68-72.

43. Kimura H, Ishibashi T, Shikama $Y$, Okano A, Akiyama $Y$, Uchida $T$ et al. Interleukin-1 beta (IL-1 beta) induces thrombocytosis in mice: possible implication of IL-6. Blood 1990; 76: 2493-2500.

44. Leven RM, Clark B, Tablin F. Effect of recombinant interleukin-6 and thrombopoietin on isolated guinea pig bone marrow megakaryocyte protein phosphorylation and proplatelet formation. Blood Cells Mol Dis 1997; 23: 252-268.

45. Heikkila K, Ebrahim S, Lawlor DA. A systematic review of the association between circulating concentrations of $C$ reactive protein and cancer. Journal of Epidemiology and Community Health 2007; 61: 824-832.

46. Black S, Kushner I, Samols D. C-reactive Protein. J Biol Chem 2004; 279 : 48487-48490.

47. Herrick S, Blanc-Brude O, Gray A, Laurent G. Fibrinogen. Int J Biochem Cell Biol 1999; 31: 741-746.

48. Wayman J, O'Hanlon D, Hayes N, Shaw I, Griffin SM. Fibrinogen levels correlate with stage of disease in patients with oesophageal cancer. Br J Surg 1997; 84: 185-188.

49. Dvorak HF, Nagy JA, Berse B, Brown LF, Yeo KT, Yeo TK et al. Vascular permeability factor, fibrin, and the pathogenesis of tumor stroma formation. Ann N Y Acad Sci 1992; 667: 101-111.

50. Sahni A, Khorana AA, Baggs RB, Peng H, Francis CW. FGF-2 binding to fibrin(ogen) is required for augmented angiogenesis. Blood 2006; 107: 126-131. 